\title{
Investigation of the Onikobe geyser, NE Japan, by observing the ground tilt and flow parameters
}

\author{
Takeshi Nishimura $^{1}$, Mie Ichihara ${ }^{2}$, and Sadato Ueki ${ }^{3}$ \\ ${ }^{1}$ Department of Geophysics, Graduate School of Science, Tohoku University, Japan \\ ${ }^{2}$ Earthquake Research Institute, University of Tokyo, Japan \\ ${ }^{3}$ Research Center for Prediction of Earthquakes and Volcanic Eruptions, Graduate School of Science, Tohoku University, Japan
}

(Received March 13, 2006; Revised April 26, 2006; Accepted April 28, 2006; Online published May 26, 2006)

\begin{abstract}
In this study we conducted observations of the Onikobe geyser, NE Japan, by deploying a tiltmeter and an acoustic sensor close to the vent, a flow pressure sensor at the conduit exit, and measuring water temperature at ground level. The data from these instruments are consistent with the model of geysers which involves effusion process of boiling due to depressurization. During the observation period, the geyser generally effused water for about $90 \mathrm{~s}$ every $10 \mathrm{mins}$, although during certain periods these times randomly shortened to about $60 \mathrm{~s}$ and 6 mins, respectively. Tilt records show a strong correlation with the short and long effusion times, reflecting water movement in at least two chambers beneath the vent. We are able to empirically predict the duration of effusion from tilt data, although flow pressure does not vary with effusion time.
\end{abstract}

Key words: Geyser, Onikobe, effusion, tilt, boiling, depressurization.

\section{Introduction}

Geyser activity is well known for intermittent activity of hot-water effusion. The effusion process looks quite similar to volcanic eruptions, and some geysers are characterized by regular interval time and duration, which are also recognized in Strombolian type eruptions and volcanic tremor. Consequently, the geyser have been widely studied using seismological and geophysical techniques, as well as field observations, not only for clarifying the mechanism of geyser but also for understanding the volcanic eruptions (e.g., Fukutomi 1942a, b, c; Kieffer, 1984; Kedar et al., 1996). Fukutomi (1942a, b, c) presented a mechanism of geyser activity by studying stationary and quasi-stationary boiling fountains in the Izu region, Japan, based on ground temperature data and the boiling conditions of water. $\mathrm{He}$ explained the intermittent effusions of geysers by successive boiling episodes related to depressurization within the conduit, into which hot water is constantly supplied from deeper levels. Kieffer (1984) investigated the Old Faithful Geyser, California, USA, and proposed the same effusion mechanism as that of Fukutomi (1942a, b, c), based on seismic data and water level and temperature data from the conduit. These pioneer works succeeded in clarifying the mechanism of geyser activity that involves the effusion of boiling water.

These previous studies are, however, based mainly on incomplete temporal data, as the direct measurement of temperature and water level within the conduit is difficult during periods of effusion. Hence, in the present study we observed tilt motions of the ground surrounding the Onikobe

Copy right(c) The Society of Geomagnetism and Earth, Planetary and Space Sciences (SGEPSS); The Seismological Society of Japan; The Volcanological Society of Japan; The Geodetic Society of Japan; The Japanese Society for Planetary Sciences; TERRAPUB geyser, NE Japan, and flow pressure at the exit of the conduit to continuously record data both leading up to and during effusion stages. We discuss the mechanism of geyser activity based on these data, and demonstrate complexity in the geyser activity that is generally characterized by regularity.

\section{Observations at the Onikobe Geyser}

We conducted temporal observations at Onikobe geyser $(38.80 \mathrm{~N}, 140.67 \mathrm{E}, 310 \mathrm{~m})$, located in Fukiage-onsen area within the Onikobe Caldera, NE Japan (Fig. 1). Geysers in Fukiage-onsen area are said to have been discovered about 1700 years ago (Nomura and Arii, 1940). The largest geyser originally effused hot water to a height of 10-13 m, but geyser activity in this region gradually weakened due to, for example, local flooding in 1910.

In 1938 a new geyser formed at a site where local residents had dug an $18 \mathrm{~m}$ borehole to create an onsen (hot spring). Since formation, this geyser, which is named Benten and generally called Onikobe geyser, has naturally effused hot water. Currently, effused hot water reaches 6$8 \mathrm{~m}$ in height at interval times of approximately $10 \mathrm{mins}$. Because this geyser is a sightseeing attraction, the exit of the conduit is channeled through an iron pipe whose top is about $1.5 \mathrm{~m}$ above the ground surface; this acts to increase the height of the effused water column. The radius of the iron pipe is about $4.2 \mathrm{~cm}$, so that the volume of the borehole is roughly estimated to be $0.1 \mathrm{~m}^{3}$.

We collected data from a tiltmeter (Pinnacle Tec., 5500) that was installed $7 \mathrm{~m}$ from the vent during April 5-6 and June 7-11 2004. The tiltmeter was embedded in a hole of about $1 \mathrm{~m}$ depth. The sampling time and resolution of tilt measurement are $1 \mathrm{~s}$ and 10 nano radian, respectively, and the tiltmeter can response the ground tilt as fast as about 


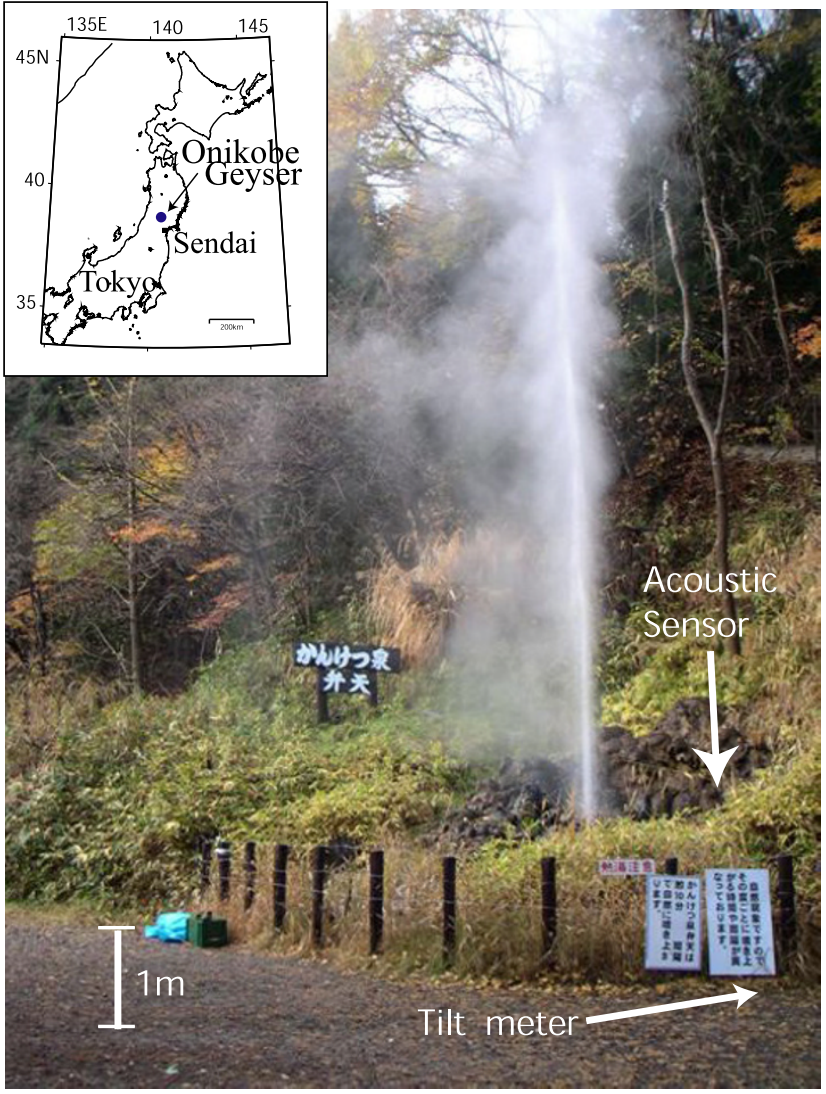

Fig. 1. Location map and photograph of water effusion from the Onikobe geyser. The water reaches a height of approximately 6-7 $\mathrm{m}$ from the ground surface.

5 s. An acoustic sensor (Type 7144, ACO Co. Ltd.) was set at about $6 \mathrm{~m}$ from the vent to record the timing of effusion events. Dynamic pressure of the flow was measured at the exit of the vent by installing an absolute pressure sensor (XTEH-7L-190-50A of Kulite Semiconductor Products. Inc.). The pressure sensor faced the flow at a small angle with the flow axis. The resolution and response time are 40 $\mathrm{Pa}$ and $0.025 \mathrm{~ms}$, respectively, according to our own tests. The sampling time was $1 \mathrm{~ms}$. DC component of output of the sensor, which corresponds to the atmospheric pressure, was removed in amplification of the signal. We also measured the temperature of geyser water, prior to each effusion event, leaking from a small hole at ground level from the iron pipe. Figure 2 shows an example of the radial component of tilt data (i.e., tilt directed to the vent), acoustic signal, and temperature of geyser water leaking from the pipe. Each effusion was preceded by a gradual increase in tilt that indicates uplift of the vent relative to the station. This suggests that hot water resides in chambers beneath the vent. The rate of recorded increase in tilt was almost constant for each effusion event during the observation period (Fig. 3). About 1 min before each effusion, water began to leak from the small hole of the iron pipe and the temperature suddenly increased to about $80^{\circ} \mathrm{C}$. The rate of leakage was initially small but gradually increased leading up to the effusion event. Water also sometimes effused from cracks in the sidewall surrounding the iron pipe. The temperature of the water from the small hole finally reached $100^{\circ} \mathrm{C}$ im-

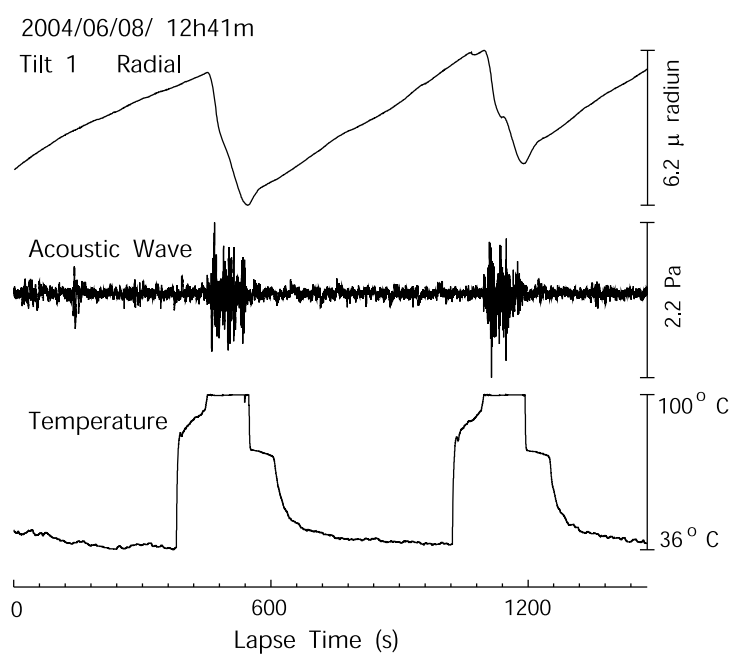

Fig. 2. Temporal changes in tilt records (radial component), acoustic signal, and water temperature over a $25 \mathrm{~min}$. Increase of tilt records corresponds to uplift of the vent to the location of tiltmeter. Accuracy of temperature measurement is about $1^{\circ} \mathrm{C}$.

mediately prior to effusion. The final temperature is nearly the same as the boiling point of pure water at Onikobe (i.e. $99^{\circ} \mathrm{C}$ ) or a little bit over it.

Each effusion event began with water flowing slowly from the top of the iron pipe. The flowing water was not boiling because the upper parts were cooled by the atmosphere and rocks surrounding the conduit. After a few seconds, water in the conduit suddenly splashed out and a period of rapid effusion began. The start time of each effusion event was well recorded by acoustic signals (Fig. 2). During each effusion event, tiltmeter recorded downward motion related to the withdrawal of hot water from chambers beneath the vent. Each effusion continued for about 50-100 $\mathrm{s}$, during which time high-frequency acoustic signals were observed and an approximately 4 micro-radian change in tilt recorded. Once the effusion was approaching its end, the tilt began to increase again. We estimated that the total volume of water effused from the geyser during each event was approximately $0.4 \mathrm{~m}^{3}$. As this volume is approximately four times greater than the volume of the borehole $\left(0.1 \mathrm{~m}^{3}\right)$, there must be water chambers beneath the vent in addition to the borehole.

Our observational data are consistent with the mechanism of geyser effusion described by Fukutomi (1942a, b, c) and Kieffer (1984): (1) prior to effusion, a constant supply of hot water from deeper levels fills the water chambers; (2) the upper parts of the water are cooled by the atmosphere and thereby act as a cap to the underlying hot water; (3) when the upper cold water exits the vent, the underlying hot water is subject to depressurization and boils; (4) boiling water within the chamber rapidly effuses; (5) once the level of hot water within the chamber has sufficiently decreased, the effusion stops and the cycle begins again. This mechanism is strongly supported by a number of our observations. Stage (1) is first verified by variations in the tilt data, while stage (2) is confirmed from the temperature of water that leaks from the pipe. Stage (5) is apparent from continuous observations of tilt motions. 
(a) Stable Period (2004/06/10/ 01h06m)

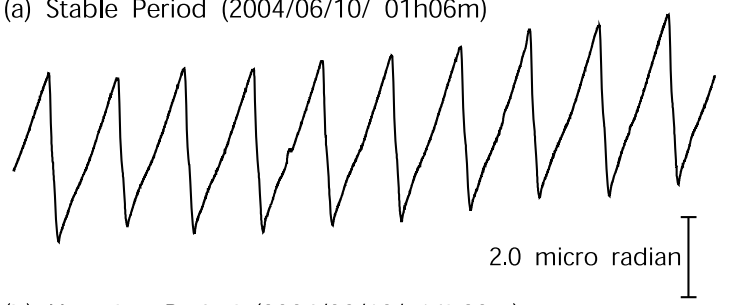

(b) Unstable Period (2004/06/10/ 14h23m)

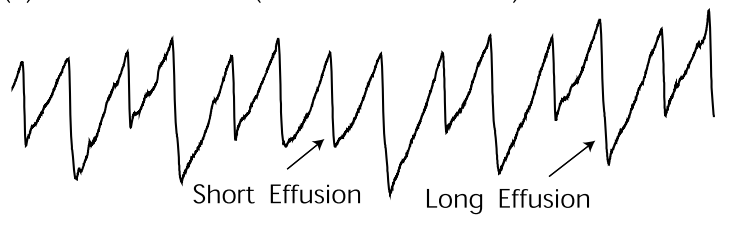

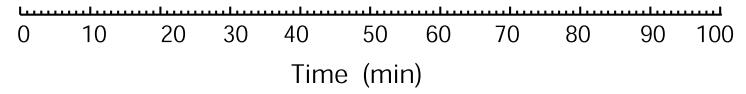

Fig. 3. Tilt records during a stable period (a) and unstable period (b).

\section{Stable and Unstable Aspects of Effusion from the Onikobe Geyser}

As apparent in the saw-toothed pattern of tilt records (Fig. 3(a)), the Onikobe geyser is generally characterized by regular activity. The interval time and duration time of effusion events were almost constant during the observation period (10 mins and $90 \mathrm{~s}$, respectively). We describe periods of regular activity as 'stable periods'; however, the interval time and duration time of effusions fluctuated during about $30 \%$ of the observation period, as shown in Fig. 3(b). During these 'unstable periods', we observed short effusions with a duration time of about 50-70 s (hereafter termed 'short effusions') and a tilt change of about 2 micro-radians, while 'long effusions' recorded typical duration times of about $80-100 \mathrm{~s}$ and tilt changes of 4 microradians. Short effusions were always followed by a preparation stage of 6-8 mins, while long effusions preceded a preparation stage of 10-12 mins. This relationship between duration of effusion and interval between effusion events indicates that the Onikobe geyser is a so-called 'time predictable system' (i.e., we can predict the time when effusion starts from the duration of previous effusion), as with the Old Faithful Geyser where the distribution of interval times of effusions is bimodal (Kieffer, 1984). However, there is no systematic pattern in the occurrence of short and long effusions.

Figure 4 shows an example of flow pressure measured at the exit of the vent. Strong pressure was recorded for about $20 \mathrm{~s}$ from the start of the effusion event (indicated by an arrow), followed by relatively weak flow pressure for $70 \mathrm{~s}$ until the effusion ended (middle and upper records in Fig. 4). The transition from strong to weak flow was also apparent from visual observation. Initial strong effusion for about $20 \mathrm{~s}$ was also observed during unstable periods (middle and lower records). The difference in flow pressure during stable and unstable periods is apparent in their respective amplitudes: pressure amplitudes for the first $20 \mathrm{~s}$ of effusion during a stable period are about twice those during an unstable period, although the initial effusion is similar in both events. In the unstable periods, some of the short effusions (al Long Effusion during Stable Period

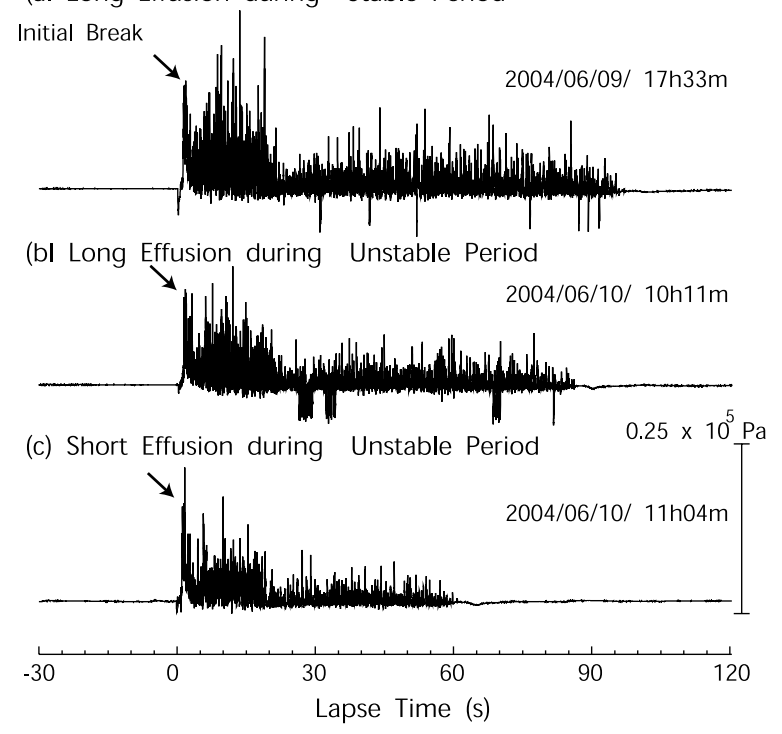

Fig. 4. Temporal variations in dynamic pressure measured at the conduit exit. The upper record was obtained during the stable period, while the middle and lower records were obtained during unstable periods. Arrows indicate initial breaks.

reduced the duration time of initial strong effusion from 20 $\mathrm{s}$ to about $13 \mathrm{~s}$, but the other short effusions showed the temporal pattern of initial effusion quite similar to those of long effusions. It is therefore difficult to predict the duration of each effusion event from surface observations alone.

Figure 5(a) shows a comparison of tilt records from short and long effusions. The starting time is adjusted to the start time of the effusion event. Both tilt records follow similar downward motions for $20 \mathrm{~s}$ from the beginning of the event; however, the tilt records begin to diverge from $20 \mathrm{~s}$ when the short effusion switches polarity and records uplift while the long effusion changes the rate of tilt but retains its polarity. The total changes in tilt for the short and long effusions are about 2 and 4 micro-radians, respectively. The ratio is almost similar to that for duration times. Figure 5(b) shows the tilt vectors for short and long effusions. At $20 \mathrm{~s}$, the tilt vectors for the long and short effusions rapidly change direction to approximately 30 and 120 degrees, respectively. These changes reflect the migration of water beneath the vent. Since the rapid change in the tilt vector at $20 \mathrm{~s}$ is not well explained by a gradual decrease in water level in the borehole or a single chamber, we infer that hot water is probably effused from at least two connected chambers beneath the vent. The tilt vector does not point to the direction of vent at the beginning, so the first chamber does not consist only of the borehole. Considering that flow pressure is strong for the initial $20 \mathrm{~s}$, we infer that the first chamber is probably a crack directly connected to the vent through the borehole. The second chamber is considered to be diagonally connected with the first chamber so as to change the direction of tilt vector when the water is effused from the second chamber.

It is noteworthy that the tilt motions for the short and long effusions begin to deviate from each other at $20 \mathrm{~s}$ from the start of effusion. As this deviation begins before the short effusion stops, we are able to empirically predict the dura- 
(a)

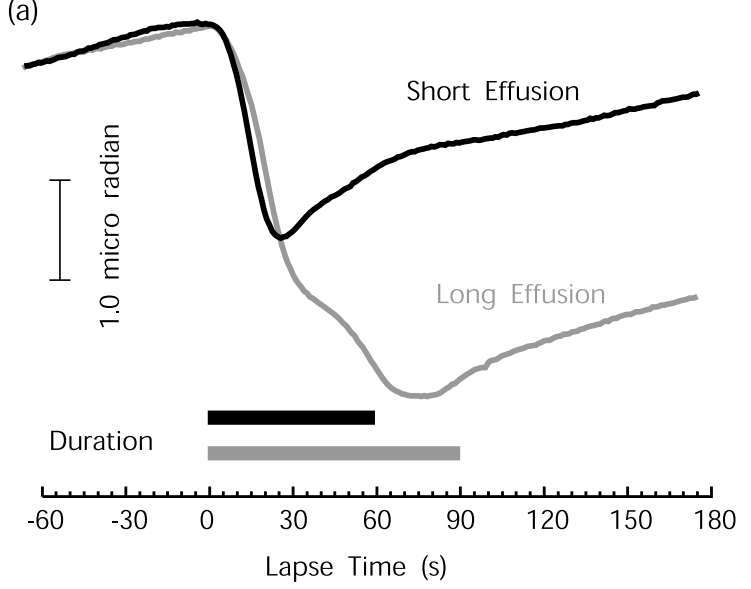

(b)

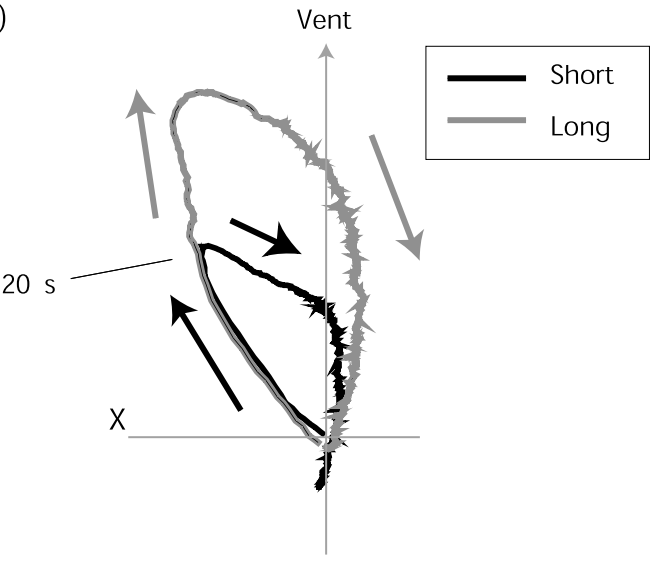

Fig. 5. Comparison of tilt records for short and long effusions. (a) Temporal changes in radial components. (b) Comparison of tilt vector records.

Unstable Period (2004/06/11/ 05h10m)

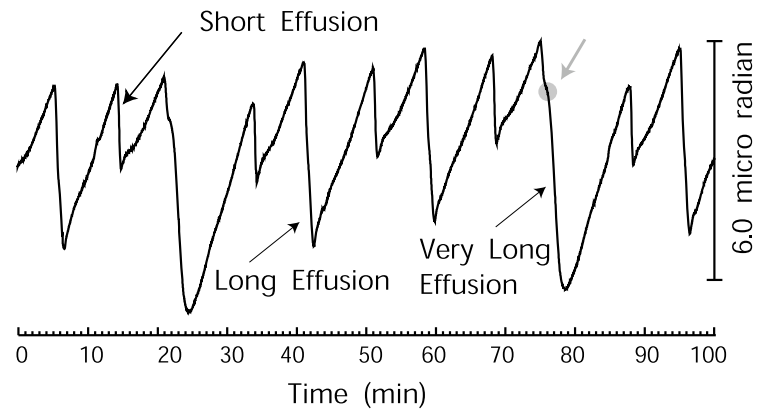

Fig. 6. Tilt records showing a very long effusion event among regular short and long effusion events.

tion of effusion from the tilt data. The short and long effusions occur randomly, so it is plausible to infer that subtle changes in the geyser system control the duration time. Although the mechanism that acts to stop continuous effusion partway through the event is unknown, fluctuations in water temperature and pressure may determine the boiling conditions of the water.

We observed a second complexity on the last day of observations at the Onikobe geyser. Figure 6 shows very long effusion that occurred among regular short and long effusions. The effusion began in the same way as short and long effusions, but began to subside at about the $30 \mathrm{~s}$ mark (see gray circle in Fig. 6) before recovering to continue for another $120 \mathrm{~s}$. The tilt records indicate large downward motions of as much as 6 micro-radians. While our observation period was very short compared with the long-lived activity of the geyser, we observed complex behaviors that are contrary to the geyser activity that is often characterized by regularity.

\section{Summary}

The main results obtained from analyses of continuous measurements of tilt data, flow pressure at the vent, acoustic data, and water temperature, are summarized as follows. (1) Data obtained at the Onikobe geyser are consistent with the effusion mechanism of boiling due to depressurization, as described in previous studies (Fukutomi, 1942a, b, c; Kieffer, 1984). (2) The Onikobe geyser generally behaves as a so-called 'time predictable system'. (3) It is possible to empirically predict the duration time of an effusion event from tilt records. (4) The geyser occasionally exhibits unstable characteristics in terms of fluctuating duration and interval times for effusion events.

Acknowledgments. We thank Mitsuhiko Oka and staffs at the Onikobe geyser house for kindly arranging our observation. Minemori Sato and Youichi Shimomura helped with installation of the instruments. Careful comments by Xinli Lu and an anonymous referee were very helpful to improve the manuscript. This study is partly supported by a Grant for Scientific Research from MEXT (No. 14080202).

\section{References}

Fukutomi, T., Two types of stationary boiling fountains at Izu region, Bull. Seism. Soc. Jpn., 14, 33-45, 1942a (in Japanese).

Fukutomi, T., A new mechanism of the geyser I, Bull. Seism. Soc. Jpn., 14, 157-174, 1942b (in Japanese).

Fukutomi, T., A new mechanism of the geyser II, Bull. Seism. Soc. Jpn., 14, 189-202, 1942c (in Japanese).

Kedar, S., B. Sturtevant, and H. Kanamori, The origin of harmonic tremor at Old Faithful geyser, Nature, 379, 708-711, 1996.

Kieffer, S., Seismicity at Old Faithful Geyser: an isolated source of geothermal noise and possible analogue of volcanic seismicity, J. Volcanol. Geotherm. Res., 22, 59-95, 1984.

Nomura, Y. and K. Arii, Study on the new Fukiage geyser of Onikobe Benten I, Current news of Saito-Hoonkai, No. 168, 1-19, 1940 (in Japanese).

T. Nishimura (e-mail: nishi@zisin.geophys.tohoku.ac.jp), M. Ichihara, and S. Ueki 